\title{
Epicuticular Waxes and Stomata of Adult Scale Leaves of the Chinese Juniper Juniperus chinensis
}

\author{
Ki Woo Kim* \\ School of Ecology and Environmental System, Kyungpook National University, Sangju 742-711, Korea
}

*Correspondence to: Kim KW

Tel: +82-54-530-1246

Fax: $+82-54-530-1248$

E-mail: kiwoo@knu.ac.kr

Received August 10, 2012

Revised August 23, 2012

Accepted September 4, 2012
Leaf surface structures were investigated in the Chinese juniper Juniperus chinensis by scanning electron microscopy. Adult scale leaves were collected from the tree, air-dried at room temperature, and sputter-coated with gold without further specimen preparation. Approximately five stomata were locally distributed and arranged in clusters on the leaf surface. Stomata were ovoid and ca. $40 \mu \mathrm{m}$ long. The epicuticular wax structures of $J$. chinensis leaves were tubules and platelets. Numerous tubules were evident on the leaf regions where stomata were found. The tubules were cylindrical, straight, and ca. $1 \mu \mathrm{m}$ in length. They almost clothed the stomatal guard cells, and occluded the slit-shaped stomatal apertures. Moreover, the wax ridges were flat crystalloids that were connected to the surface by their narrow side. They did not have distinct edges, and their width/height ratio varied. In particular, the wax ridges could be discerned on the leaf regions where stomata were not present nearby. Since the wax ridges did not have distinct edges on their margin, they were identified as platelets. Instances were noted where platelets were oriented either parallel to each other or perpendicular to the cuticle surface. These results can be used in biomimetics to design the hierarchical structures for mimicking the plant innate properties such as hydrophobicity and self-cleaning effects of the leaf surface.

Key Words: Juniperus chinensis, Stomata, Wax

\section{INTRODUCTION}

Plants are continuously exposed to a wide variety of biotic or abiotic signals in their positions during their lifetime. The plant cuticle is a multifunctional interface between a plant and its atmospheric environment (Riding \& Percy, 1985). The cuticle is covered by epicuticular waxes with considerable ultrastructural and chemical diversity (Barthlott et al., 1998). Some waxes are embedded in the cuticle (intracuticular waxes), and others are deposited on the cuticular surface (epicuticular waxes) (Kim, 2008). As the outermost layer of plant surfaces, the epicuticular waxes strongly affect the (i) surface wettability, (ii) adhesion of particles, pathogens, and insects on the leaves, (iii) self-cleaning properties, and (iv) reflection or absorption of light (Koch et al., 2009).
Depending on plant taxa, their micromorphologies are diverse ranging from platelets, rodlets, and tubules to rosettes (Barthlott et al., 1998). In most cases, plant waxes are a complex mixture of long-chain aliphatic compounds, such as $n$-alkanes, fatty acids, alcohols, aldehydes, ketones or $n$-alkyl esters (Dragota \& Riederer, 2007). A common feature of the epicuticular waxes is that the three-dimensional wax structures reside on an underlying two-dimensional closed wax film of less than $1.0 \mu \mathrm{m}$ in thickness (Koch et al., 2009). Native to northeast Asia, the Chinese juniper Juniperus chinensis is one of the most popular ornamental trees in gardens and parks worldwide. The tree species belongs to the family Cupressaceae, and represents a coniferous evergreen shrub. Mature trees bear adult leaves with scales (adult scale leaf) and berry-like cones. The adult scale leaves commonly

This work was supported by the Kyungpook National University Research Grant, 2012.

(a) This is an open-access article distributed under the terms of the Creative Commons Attribution Non-Commercial License (http://creativecommons.org/licenses/by-nc/3.0) which permits unrestricted noncommercial use, distribution, and reproduction in any medium, provided the original work is properly cited.

Copyrights @ 2012 by Korean Society of Microscopy 


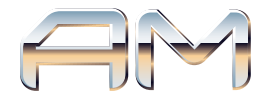

exhibit several xeromorphic characteristics such as (i) small and compact shape, (ii) reduced surface area, (iii) closely oppressed and overlapping leaves, (iv) thick cuticle, and (v) small numbers of sunken stomata in protected regions (Miller et al., 1995). Divergent alkane chain length was reported from J. communis leaves (Dodd \& Poveda, 2003). The epicuticular waxes of J. scopulorum leaves contained hydrocarbons, esters, free acids, nonacosan-10-ol, nonacosane-diols, and estolides (Tulloch \& Bergter, 1981).

It is necessary to gain a fundamental knowledge on the surface structures on the adult scale leaves for a better understanding of the tree-environment interactions in nature. Leaf surface observations can provide a clue to establishing hypotheses on the natural openings and innate defense machinery against microbial pathogen attack. However, few reports are available on the detailed micromorphological descriptions of stomata and epicuticular waxes on leaves of Juniperus species. Here, I report the micromorphology of epicuticular waxes of mature foliage of J. chinensis by scanning electron microscopy.
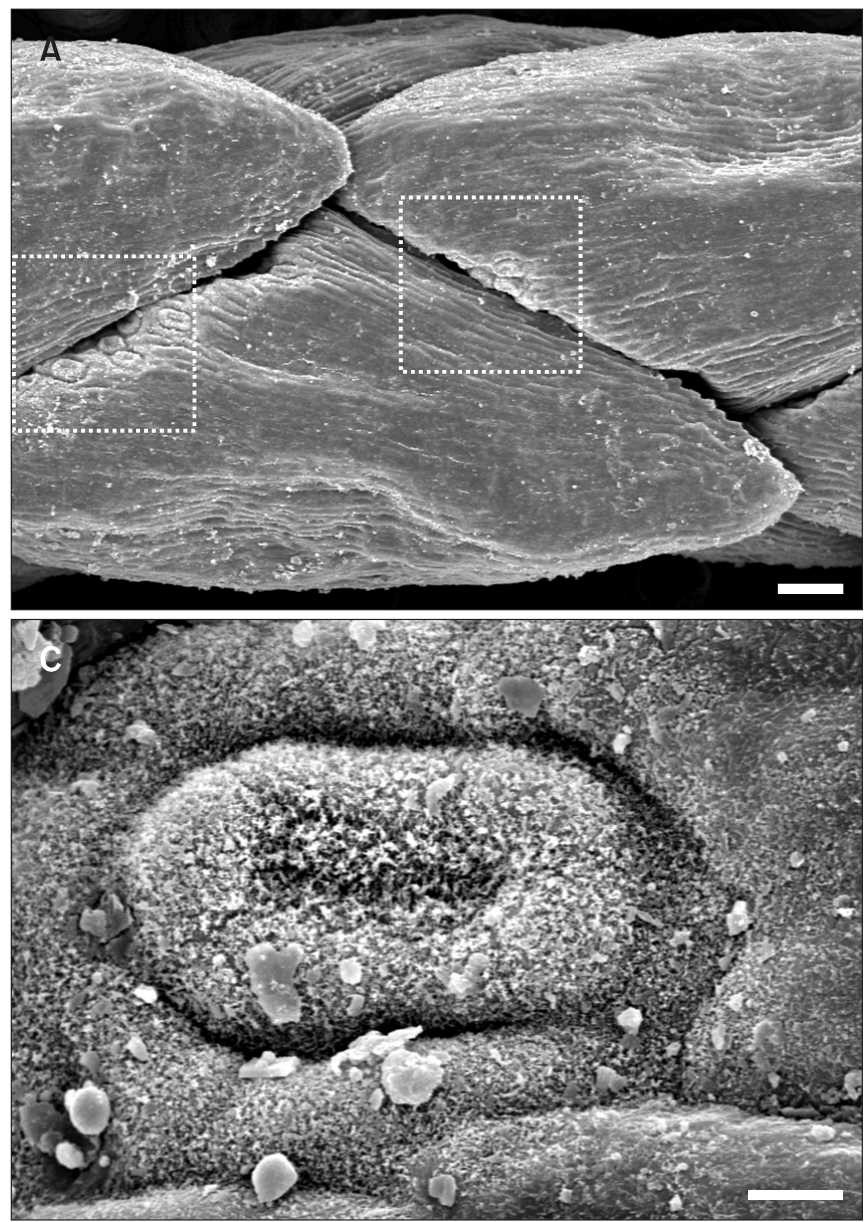

Fig. 2. Scanning electron micrographs of Juniperus chinensis. (A) Adult scale leaf. Stomata are locally present on the leaf surface (dotted rectangles). Bar $=100 \mu \mathrm{m}$. (B) Stomata. Arrows and arrowheads indicate stomatal guard cells and stomatal pores, respectively. Bar=10 $\mu \mathrm{m}$. (C) Stoma. Epicuticular waxes are prevalent on the stomatal complex. Bar $=10 \mu \mathrm{m}$. 
$\sqrt{2}-2+$

\section{MATERIALS AND METHODS}

\section{Plant Materials}

Leaves of J. chinensis were collected from a ca. 10-year-old tree in Seoul, Korea. The tree overall showed normal growth under natural sunlight. Preferably adult scale leaves were taken from the middle part of the plant. The leaf surface was gently blown to remove dust and dirt using a hand-held blower, and
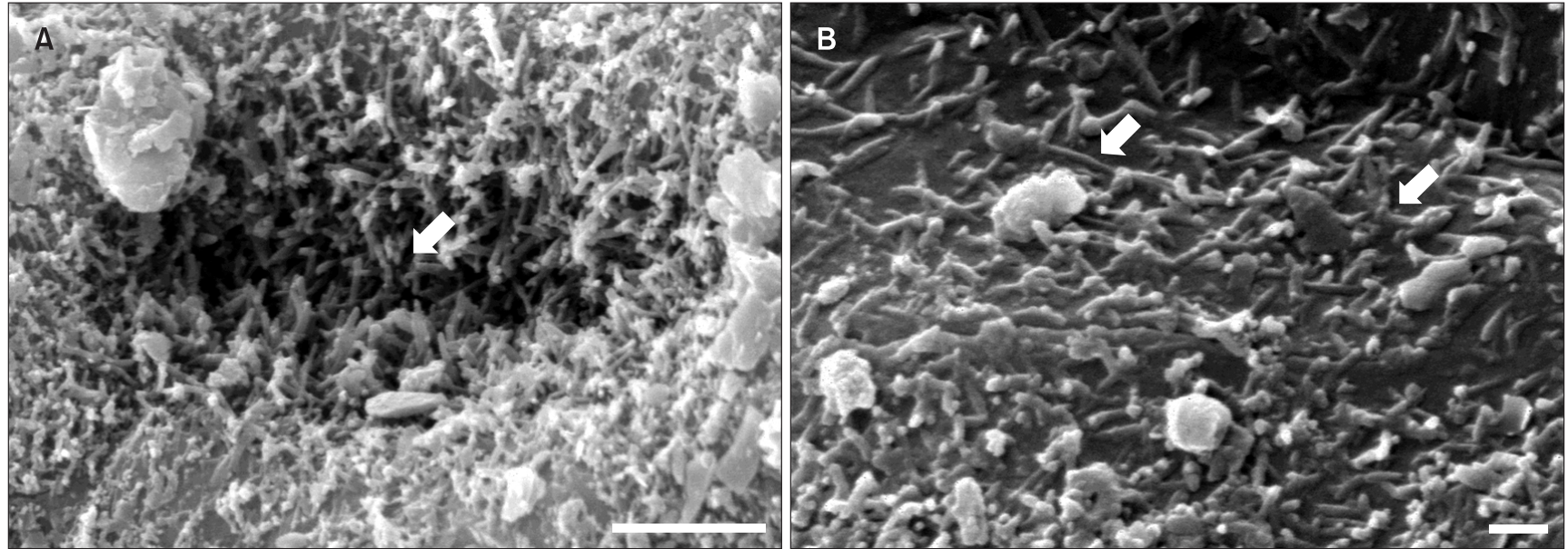

Fig. 3. Scanning electron micrographs of Juniperus chinensis. (A) Stomatal pore. Epicuticular waxes almost covered the stomatal pore (an arrow). Bar=5 $\mu \mathrm{m}$. (B) Epicuticular waxes on the stomatal guard cell. Numerous rod-shaped waxes (arrows) are present on the cell surface. Bar=1 $\mu \mathrm{m}$.
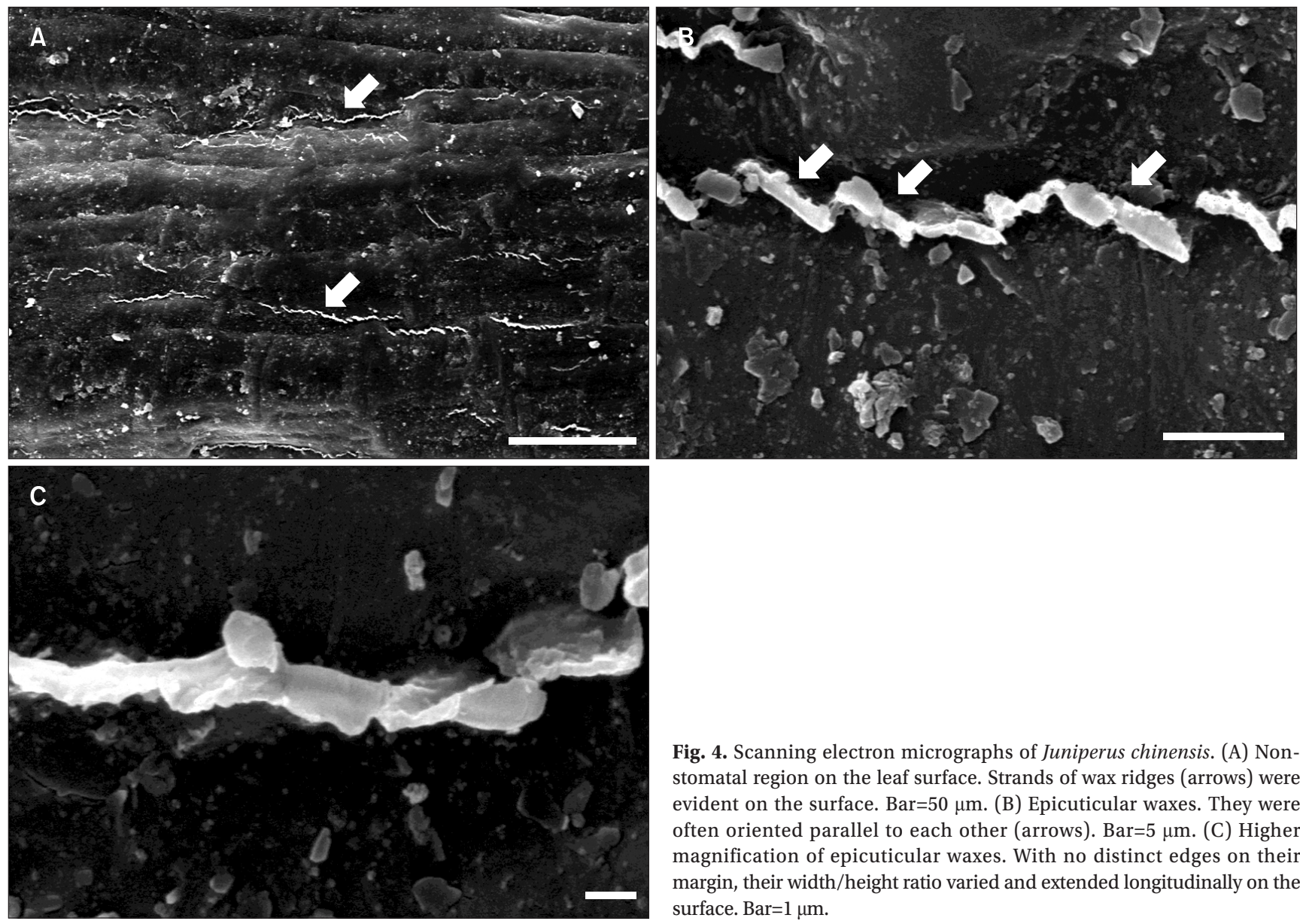

Fig. 4. Scanning electron micrographs of Juniperus chinensis. (A) Nonstomatal region on the leaf surface. Strands of wax ridges (arrows) were evident on the surface. Bar=50 $\mu \mathrm{m}$. (B) Epicuticular waxes. They were often oriented parallel to each other (arrows). Bar=5 $\mu \mathrm{m}$. (C) Higher magnification of epicuticular waxes. With no distinct edges on their margin, their width/height ratio varied and extended longitudinally on the surface. Bar $=1 \mu \mathrm{m}$. 
air-dried at room temperature for two months.

\section{Scanning Electron Microscopy}

Leaf fragments (ca. $5 \mathrm{~mm}$ long) were excised using a razor blade from the plant. To avoid structural alterations of the epicuticular waxes during conventional specimen preparation, air-dried leaves were used as reported previously (Kim et al., 2011a). The specimens were mounted on a metal stub (10 $\mathrm{mm}$ in diameter) using two-sided adhesive carbon tape. They were sputter-coated with gold (ca. $30 \mathrm{~nm}$ in thickness), and examined with a scanning electron microscope (JSM-5410LV, JEOL Ltd., Tokyo, Japan) at an accelerating voltage of 20 $\mathrm{kV}$. Secondary electron images were recorded using a digital image processor (analySIS, Soft Imaging System GmbH Ltd., Münster, Germany).

\section{RESULTS}

Mature foliage of $J$. chinensis had membranous scale-like leaves on the surface (Fig. 1). Each scale leaf was green, pointed, and ca. $500 \mu \mathrm{m}$ wide. Scanning electron microscopy revealed the surface details of the adult scale leaves (Fig. 2A). The small amount of surface dirt remained on the leaf surface. Approximately five stomata were locally distributed and arranged in clusters on the leaf surface. Stomata were ovoid and ca. $40 \mu \mathrm{m}$ long (Fig. 2B). Stomatal guard cells encircling stomatal pores were distinctly elevated from the neighboring epidermis. Epicuticular waxes clothed the stomatal complex including the stomatal guard cells, stomatal pores, and their surrounding regions (Fig. 2C). Due to the epicuticular waxes, the stomatal complex overall had a fluffy appearance.

Higher magnifications showed that the epicuticular waxes almost occluded the stomatal pores (Fig. 3A). The inner details of the stomatal chamber could be hardly discerned due to the accumulated epicuticular waxes. The epicuticular waxes appeared mostly straight and cylindrical (Fig. 3B). They showed uniform dimensions (ca. $1 \mu \mathrm{m}$ in length).

Another type of epicuticular waxes was observed in certain regions on the leaf surface. Strands of wax ridges were found on the non-stomatal regions where stomata were not present nearby (Fig. 4A). The wax ridges appeared to be flat crystalloids connected to the surface by their narrow side (Fig. 4B). They were often oriented parallel to each other. With no distinct edges on their margin, the wax ridges protruded perpendicularly from the surface (Fig. 4C). Their width/ height ratio varied and extended longitudinally on the nonstomatal regions.

\section{DISCUSSION}

This study demonstrated the micromorphological characteristics of stomata and epicuticular waxes of adult scale leaves of $J$. chinensis by scanning electron microscopy. According to the classification and terminology of plant epicuticular waxes by Barthlott et al. (1998), the epicuticular waxes of adult scale leaves of J. chinensis could be categorized to (i) tubules and (ii) platelets. Tubules were characterized by the cylindrical and (slightly) straight shapes. Due to the micromorphological similarity with rodlets, tubules were usually misidentified as rodlets in various publications (Barthlott et al., 1998). Rodlets are massive sculptures with a length/width ratio usually not exceeding 50:1 (Barthlott et al., 1998). Based on the shape and a length/width ratio not exceeding 10:1 (data not shown), the short and thin rod-shaped waxes were identified as tubules.

Meanwhile, the wax ridges were flat and attached to the surface by their side. The occurrence of similar wax platelets was also reported from the leaves of Pinus koraiensis (Kim et al., 2011b), Pinus palustris (Prior et al., 1997), and Pinus sylvestris (Lin et al., 2001). These ridges were found on the non-stomatal regions of the conifer leaves, which was consistent with the results in this study. In spite of the reports of the wax ridges from the plants, there was no classification of the wax type based on the micromorphological criteria. Given the dull edges on their margin, the wax ridges could be designated as 'platelets'. Plates having distinct edges on their margin were not observed in this study. The significance and implications of platelets with leaf topology will be investigated in further studies.

It was apparent in this study that different types of epicuticular waxes had their own different distribution patterns on the leaf surface depending on the specific regions (stomatal regions and non-stomatal regions). Tubules were present on the stomatal regions, whereas platelets were found on the nonstomatal regions. Such a co-occurrence of different types of epicuticular waxes on different regions of the plant has been called syntopism, as shown in other plants (Barthlott et al., 1998; Kim et al., 2011b). It remains unclear whether epicuticular waxes differing in shape have different chemical compositions (Barthlott et al., 1998). To my knowledge, this is the first report on the micromorphological characterization of the leaf epicuticular waxes of J. chinensis by scanning electron microscopy.

An intriguing finding in this study was the aggregation pattern of stomata on the leaf surface. The stomata on the needle leaves of Pinus species were positioned in rows (Kim et al., 2010, 2011a, 2011b). The adult scale leaves exhibited an uneven, local distribution of aggregations of stomata. It is reasonable to state that the stomata positions represent protected regions against sunlight irradiation and desiccation under natural conditions, as suggested from $J$. occidentalis (Miller et al., 1995). Furthermore, the accumulated epicuticular waxes in the stomatal apertures seemed to be partially contributing to the prevention of transpiration through the stomata of the plant. 
In summary, this study provided a detailed description of surface structures of the adult scale leave of J. chinensis. Combined micromorphological characteristics of stomata and epicuticular waxes are responsible for the xeromorphic nature of the adult scale leaves. These results can be used in biomimetics to design the hierarchical structures for mimicking the plant innate properties such as hydrophobicity and self-cleaning effects of the leaf surface. Elucidation of the mechanisms underlying the synthesis of the different types of the epicuticular waxes will enhance the understanding of structure-function relationships of leaf surface structures of plants.

\section{CONCLUSIONS}

The stomata of the Chinese juniper J. chinensis showed local distribution on the adult leaf surface. Ovoid in shape, they formed clusters and had distinctly elevated stomatal guard cells. The epicuticular waxes were prevalent on the leaf surface, and almost occluded the stomatal apertures. Tubules were present on the stomatal regions, whereas platelets were found on the non-stomatal regions. These surface structures may contribute to the xeromorphic nature of the adult scale leaves of the tree species.

\section{ACKNOWLEDGMENTS}

I am grateful to Geun Ae Jang in the National Instrumentation Center for Environmental Management at Seoul National University, Korea for providing the plant materials.

\section{REFERENCES}

Barthlott W, Neinhuis C, Cutler D, Ditsch F, Meusel I, Theisen I, and Wilhelmi H (1998) Classification and terminology of plant epicuticular waxes. Bot. J. Linn. Soc. 126, 237-260.

Dodd R S and Poveda M M (2003) Environmental gradients and population divergence contribute to variation in cuticular wax composition in Juniperus communis. Biochem. Syst. Ecol. 31, 12571270.

Dragota S and Riederer M (2007) Epicuticular wax crystals of Wollemia nobilis: morphology and chemcial composition. Ann. Bot. 100, 225231.

Kim K W (2008) Visualization of micromorphology of leaf epicuticular waxes of the rubber tree Ficus elastica by electron microscopy. Micron. 39, 976-984.

Kim K W, Kim D H, Han S S, Lee J C, and Kim P G (2010) Three-dimensional surface topography of the needle stomatal complexes of Pinus rigida and its hybrid species by complementary microscopy. Micron. 41, 571-576.

Kim K W, Lee I J, Kim C S, Lee D K, and Park E W (2011a) Micromorphology of epicuticular waxes and epistomatal chambers of pine species by electron microscopy and white light scanning interferometry. Microsc. Microanal. 17, 118-124.

Kim K W, Lee S T, Bae S W, and Kim P G (2011b) 3D surface profiling and high resolution imaging for refining the Florin rings and epicuticular wax crystals of Pinus koraiensis. Microsc. Res. Techniq. 74, 11661173.

Koch K, Dommisse A, Niemietz A, Barthlott W, and Wandelt K (2009) Nanostructure of epicuticular plant waxes: self-assembly of wax tubules. Surf. Sci. 603, 1961-1968.

Lin J, Jach M E, and Ceulemans R (2001) Stomatal density and needle anatomy of Scot pine (Pinus sylvestris) are affected by elevated $\mathrm{CO}_{2}$. New Phytol. 150, 665-674.

Miller P M, Eddleman L E, and Miller J M (1995) Juniperus occidentalis juvenile foliage: advantages and disadvantages for a stress-tolerant, invasive conifer. Can. J. For. Res. 25, 470-479.

Prior S A, Pritchard S G, Runion G B, Rogers H H, and Mitchell R J (1997) Influence of atmospheric $\mathrm{CO}_{2}$ enrichment, soil $\mathrm{N}$, and water stress on needle surface wax formation in Pinus palustris (Pinaceae). Am. J. Bot. 84, 1070-1077.

Riding R T and Percy K E (1985) Effects of SO2 and other air pollutants on the morphology of epicuticular waxes on needles of Pinus strobus and Pinus banksiana. New Phytol. 9, 555-563.

Tulloch A P and Bergter L (1981) Epicuticular wax of Juniperus scopulorum. Phytochemistry 20, 2711-2716. 